\title{
Concepts of Digital Labour: Schelling's Naturphilosophie
}

\author{
Kevin Mitchell
}

\author{
Trent University, Peterborough, Canada, kevinmitchell@trentu.ca
}

\begin{abstract}
This paper uses F.W.J. Schelling's Naturphilsophie as a point of departure for theorizing the concept of digital labour. Beginning with Marx's distinction between fulfilling and unfulfilling labour, it is argued that the former is labour immanent to, and in line with, Schelling's notion of Nature as process and ungrounded ground, while unfulfilling labour externalizes Nature and attempts to use it against itself in the service of capital and the establishment of what I call a state-of-power. Schelling's The Ages of the World is re-interpreted by exchanging Schelling's notion of immaterial spirituality for digital virtuality, whereby digital labour is viewed as a consequence of previous forms of world historical developments in their entire contingency. While digital virtuality is in fact materialist in terms of both the labour that activates it and the substrate that sustains it, the materiality of the digital is often overlooked in favour of an implicit anti-materialist stance that works to disconnect the digital labourer from their online activity, and precludes the critical self-awareness necessary for an acknowledgement of their "playful" online activity as labour. The paper ends with an analysis of Mark Zuckerberg's ideational attempt to "re-wire" the world via Facebook's digital infrastructure, which begins (and/or attempts) to set the conditions of possibility for inter-personal interaction, and explores the possibilities for resistance available within Foucault's concept of the care of the self.
\end{abstract}

Keywords: Digital Labour, Immaterial Work, Marx, F.W.J. Schelling, Digital Virtuality, Social Media, Mark Zuckerberg, State-of-Power

\section{Introduction}

In the Grundrisse, Marx notes that there is an inherently contradictory status of labour: On one hand there is "repulsive [...] external forced labour," which is contrary to the labourer's own nature. On the other hand, there is "attractive work [...] which contributes to the individual's self-realization" (Marx 1986, 59-60). While externally forced labour utilizes labour power in a way that alienates the labourer from the wares of his or her work, attractive work "appears in the production process not in a merely natural, spontaneous form, but as an activity regulating all the forces of nature" $(60)$. While in both instances the status of the labourer is in an ambiguous position with relation to nature (a "merely natural, spontaneous form," and "regulating the forces of nature"), the labourer is in both cases (externally forced and internally attractive) considered to be working through the forces of nature-not on it. Taking this a step further, whether negative or positive work, Marx's labourer works immanently in and as nature, and may even be said to work through nature in such a way that the labouring activity coincides with the creative activity of nature itself.

In a similar way Schelling states that: "To philosophize about nature means to create nature [...] to heave it out of the dead mechanism to which it seems predisposed, to quicken it with freedom and to set it into its own free development-to philosophize about nature means, in other words, to tear yourself away from the common view which discerns in nature only what happens-and which, at most, views the act as a factum, not the action itself in its acting" (Schelling 2004, 14-15). Schelling considers the activity of nature to be its defining characteristic. In his Naturphilosophie, nature is immanent to the process of its productive development such that it could be said that it is nothing other than this process. Instead of remaining passively contemplative, the active labour of philosophy for Schelling is an attempt to match the relentless process of nature, which is ceaselessly active and creatively productive. Philosophizing thus takes place alongside the activity of nature, rather than in a purely contemplative (and externally alienating) form. Schelling implies that philosophizing about 
nature is a form of work-akin to Marx's "attractive work"1_-since both physical and philosophical work is conducive to "the individual's self-realization" if they are in line with, and take their impulse from, the creative force(s) of nature. This distinction also resonates with the Aristotelian distinction between "poísesis (the creation of works from nature) and praxis (selfdetermined action)" (Fuchs and Sevignani 2013, 238). While this conceptual distinction mirrors the civilization from which it arose (Fuchs and Sevignani 2013), it also, crucially, disconnects self-determined action from its immediate relation to nature. Contrary to this view, for both Marx and Schelling alike, there is a form of self-determined work that coincides with nature. For Marx, "attractive work" leads to the "self-realization" of the worker. For Schelling, authentic work participates in the process of nature's productive activity; since the worker is part of the very same nature of this activity, the worker participates in (and thereby embodies) his/her own nature. This participatory embodiment is at the opposite end of the spectrum from the alienated form of labour where the worker, while ontologically inseparable from $\mathrm{Na}$ ture's role in the labour process, is nevertheless disconnected from this same Nature in terms of the result (capitalistic accumulation), and the relationship between the worker and his/her own working body. As will be explained in detail below, the alienation that arises as a result of the state-of-power, ossifying Nature's productivity and using it against itself, results in both a social alienation (man from man in the form of an overall state of securitization) as well as man-Nature and Nature from itself. When Nature is reified, and thereby treated as object, Nature's inherent productivity becomes disconnected from itself, and accumulated by one part at the expense of another. This disconnection implies a crisis and a resultant tendency toward a form of resolution in terms of digital virtuality.

Following Christian Fuchs (2013), I will argue that there is indeed a difference between labour and work, and that one viable place to study this difference is found in Schelling's Naturphilosophie when read in conjunction with Marx's theorization, and taxonomy, of different types of labour and their historic conditions of possibility. Briefly, Fuchs and Sevignani point out that there is only one word for work/labour in German: Arbeit. Following the English language's two terms (work and labour), Engels distinguishes between work (which is qualitative and produces use-value) and labour (which is quantitative and produces exchangevalue) (Fuchs and Sevignani 2013, 240). I will consider the implications of this distinction, in the context of immaterial labour, and what may be called the proletariatization of the digital, or the progressive co-opting of Internet activity in the service of capital. I believe this analysis can contribute to the development of a conceptual framework in which these new types of labour may be studied, categorized and understood. I will also indicate some of the advantages of using Schelling to compliment a Marxist understanding of digital labour.

\subsection{Against Essentialism}

Contrary to Aristotelian essentialism, which holds that things have an inherent structure informing them as to what they are, Marx follows Hegel in emphasizing the active and changing status of entities by emphasizing their developmental character. According to this view, entities are not finished once and for all in terms of what they can be, but are the result of historical circumstances operating as their conditions of possibility. Implicated in this analysis is the view that historical phenomena are incomplete, and therefore, are inherently capable of becoming other than they are when moulded in different contexts, temporalities and spaces/placements. This view problematizes the doctrine of identity, which holds that entities have a unitary continuity across temporal instants, and against this, emphasizes difference, contingency, and contradiction. Not only are they emphasized, it is argued that these qualities are inherent to nature and result from the fundamental contingency of reality-a contingency considered by Hegel to be a sign of their vitality. Things are alive when they are capa-

\footnotetext{
${ }^{1}$ This is not to imply that Marx held that philosophizing was a form of work, his famous move to turn Hegel on his head is a move in the opposite direction, since he views philosophy as merely interpreting the world. Schelling on the other hand holds that philosophy is an active creation of nature since it is a manifestation of a higher potency, immanently operating on it as it operates on itself.
} 
ble of change (whether autonomously brought upon by themselves, or externally, by another force acting upon them).

According to this variant of anti-essentialist Hegelianism, to be alive is to be in contradiction. Italian Marxist philosopher Lucio Colletti explains the difference between the doctrine of identity and dialectical materialism thus: "As against contradiction, identity is merely the determination of the simple immediate, of dead being; but contradiction is the root of all movement and vitality" (Colletti 1979, 21). Remarking upon the Hegelian precedents of dialectical materialism, Colletti argues that for Hegel and Marx alike, the material world is not an array of static entities, as in the Aristotelian worldview, but an inter-active network of incomplete entities in disjunctive relation with each other. The inter-active nature of materiality is considered by early dialectical materialists to be the main ingredient for the auto-poietic selfmovement of Nature, and historically situated entities. In this view, the essence of a thing is determined not by what it is, but by what it becomes through its interaction with other entities, in a situation of mutually implicating development.

The analysis of digital labour in this paper highlights the vital process of nature as a constituent presupposition for the infrastructure of the digital, ${ }^{2}$ especially as the former relates to the German Idealist precedents of the Marxist tradition. From this perspective, the two types of labour identified above (externally forced and internally attractive) may be considered to be either dead or alive labour: Repulsive, externally forced labour is dead because it treats both the labour process and the labourer as finished products, while attractive work acknowledges the open-ended nature of the labour process and its inherent potential for selffulfillment through work. In both cases the main question to ask is whether the work philosophizes alongside nature, thereby contributing to the creation of nature itself, or whether it attempts to dominate it, thereby determining it as a dead and static object cut off from the vitality of life. As we shall see, Schelling's Naturphilosophie is helpful because it offers a novel conceptualization of labour and work, whereby it is grounded in the process of nature (instead of treating it as objective material to be worked over and transformed), as well as the conceptual infrastructure for a re-worked notion of natural production.

However, how could dead labour exist within a theory of labour such as Schelling's, which sees labour as immanently grounded in nature such that there is no separation between worker and nature? This contradiction is resolved when it is recalled that labour is dead only as part of a second-order operation which treats it as a product (abstracted from the production process) and detached from nature's immediate activity, thereby using it against itself (section 1.1.1.). In this way it could be argued that Schelling's distinction between authentic and dead labour is consistent with Engel's formulation of the distinction between qualitative work grounded in the necessities of nature that produces use-values, and quantitative labour, which is leveraged in the service of exchange-value capitalistic accumulation (the objectification of living work into dead labour). In both cases the natural form of work, which meets the requirements for the sustenance of life, becomes subverted from this course and re-directed in the service of the accumulation of capital, i.e. the divorce of energy (labour and time) from life. As we will see, a state of power secures this accumulation and uses it against nature, thereby disconnecting nature from itself in a version of what Adorno called the "domination" of nature (Adorno 2005).

Since "dead" labour seems to imply a disconnection of the labourer and nature, even though they are both fundamentally part of the same substrate, this disconnection is possible by means of reverse process that moves against nature by treating it as finished product and not active production. Within the terms of Schelling's philosophy, while work is immanent to nature (and to philosophize about nature is to create it), the instrumental rationality of semiocapitalism is not philosophy, and therefore treats nature and labourer as resources, or means rather than ends facilitated by algorithmic infrastructure put in place to harness the virtual version of the general intellect and oversee its valorisation. While there is no real separation

\footnotetext{
${ }^{2}$ What I mean by this is that the digital is related to, and to a certain degree, is actually reliant on materiality for its existence. This differs from the sometimes held assumption that digital computing is "clean" because it somehow exists in a "cloud" that does not require an extensive network of mass energy-consuming computers to house it.
} 
between the two (nature and work/labour), there is a virtual disconnect made possible by the condensation of a state of power and "rewiring" (section 2.1.).

In conjunction with Naturphilosophie's emphasis on process, Marx argues that "nothing can result at the end of a process that did not occur at its beginning as a prerequisite and condition" (Marx 1986, 78). In other words, process is cumulative since it presupposes what has come before in order for what comes later to be possible. As he puts it, "the result must contain all the elements of the process" (Marx 1986). The process of capitalist production follows this pattern as well, since it preserves what exists before in the form of raw material to be utilized and commoditized. In opposition to the Aristotelian notion of the self-identity of objects, for Marx, objects, ideas and socio-cultural realities are not self-subsistent entities, but are manifestations of their historical conditions. Since these conditions are indeed historical, they are contingent, and as such, objects, ideas and socio-cultural realities are capable of being actualized otherwise.

There are three aspects to Marx's emphasis on process that should be kept in mind. First, process is cumulative; there is a relative continuity of accumulation moving from the past (what happened prior) toward the future (what happens in and as the result). Second, elements that are influential at the beginning may have their effect felt throughout the process, and they continually impact the result. There is therefore a form of archive occurring in the process. Third, since process is cumulative and archiving, it is also holistic (it is more than the sum of its parts) and transcendental (the archive acts as the condition of possibility for what emerges as its result). As such, any historical entity must be considered in these terms, individually, and in conjunction with each other. Accordingly, a product is an actualization of the material conditions of possibility that have gone into making it possible, including the contradictory forces that played a role in its origination and which has come to act as its ground.

While it is true that Schelling may be read as a philosopher of substance, albeit one that is dynamic and ceaselessly changing, it is not clear what the advantages of this interpretation are. Although it is evident that he never abandoned his conception of a divine principle presenting itself through all levels of nature's manifestation (inorganic, organic, and intelligent), his work is better interpreted as one whose main concern is that of freedom, and the question of how to it is possible to reconcile a non-essential conception of nature with that of an ungrounded system. As Heidegger points out in his lectures on Schelling, at first glance it appears contradictory to pursue a system of freedom (Heidegger 1985, 22). Schelling wanted to find an ontological and philosophical ("scientific") definition of freedom, one that emerged out of a rigorous and systematic analysis of the world in all its connections. It thus required him to clarify the reason for his anti-essentialist stance by looking at the productivity of nature itself without treating it as object, and without dissecting it (only) in terms of the empirical method (although it played a role in his Naturphilosophie). As such, it was necessary to disagree with his long-admired friend Fichte, whose own subjective idealism began with the subject, and then went on to derive nature therefrom. Exchanging the primacy of the subject for that of nature, Schelling's Naturphilosophie derives the Fichtean transcendental subject from nature itself, putting nature in the position of the condition of possibility for later variants of the post-Kantian idealist theme. Therefore, for Schelling, substance takes a back seat to existence, and as the old existentialist adage put it: Existence precedes essence. There is a difference between substance and essence: While essence has to do with what a thing is in terms of its mode of being, substance indicates the underlying substrate of a thing (including its matter). However, if the essence of substance is its ungroundedness, and therefore its inherent freedom (both in-itself, and that to which it gives rise), nothing is added to the argument by stating that Schelling is a thinker of a (non-substantial) substance. However, if we say that there is such an infinitely creative universal substance, this universal substance would be defined by its existence, insofar as it comes to "know" itself in its existential mode as ceaselessly productive nature. "It is not me who knows, but only the Universe knows within me [...] This one knowledge however that knows is at the same time what is truly known" (Zimmermann 2005, 36-37). The divine Lebenskraft is immanent to the movement of nature in its self-overcoming, and auto-poietic organization. 


\subsubsection{Schelling's Ungrund_-Ungrounded Ground'}

Throughout his continual attempts to philosophize about, and thereby create nature, Schelling characterized nature in a variety of ways. In First Outline of a System for the Philosophy of Nature (Schelling 2004) for example, he variously characterizes nature as having an "absolutely productive character" (Schelling 2004,5 ) and "reproducing itself anew in each successive phase" (Schelling 2004, xix). He also depicts it as "struggling against everything individual" (Schelling 2004, 6), and as "unconditioned", such that "every individual is a particular expression of it" (Schelling 2004, 13). What these descriptions of nature have in common is that they all portray nature as primary (in relation to "products") and undifferentiated; or, what amounts to the same thing, a manifestation of pure difference, since it is that which gives rise to all individual differences: "Nature exists nowhere as product; all individual productions in Nature are merely apparent products" (Schelling 2004, 16).

Nature, according to Schelling, is also absolute activity. Since all activity is productive in some way (action takes place in relation to an environment presupposed for the action), nature's activity also leads to the production of products. In this sense, to be a product is to be produced by nature's ceaseless activity. Schelling relates the notion of absolute activity to infinity: nature's productive activity has neither beginning nor end. While nature's productive activity terminates in finite products, nature itself does not thereby stop its onslaught of production. Even products that have a veneer of being finished or complete continue to partake in nature's ceaseless activity, and are therefore only ever apparently finished products. ${ }^{3}$ Although products are also in a continual state of internal strife, they are nonetheless finite, and demarcated as limited in relation to the infinite activity of nature. However, since the infinite activity of nature resides even in its products, "every product that now appears fixed in $\mathrm{Na}$ ture would exist only for a moment, gripped in continuous evolution, always changeable, appearing only to fade away again" (Schelling 2004, 18). Products are temporary lapses.

Schelling provides the following example to illustrate the way the underlying forces of nature operate productively: "A stream flows in a straight line forward as long as it encounters no resistance. Where there is resistance-a whirlpool forms. Every original product of nature is such a whirlpool" (Schelling 2004, 18). It is through the activity of nature that products are able to participate in the activity of nature, and it is through work that the human being-as a product of nature in the midst of other products-strives to preserve itself as a formal entity in the midst of nature's ceaseless productive activity. By participating in this activity in its own way, the human is able to limit itself from the infinite activity by producing boundaries (between itself as organism) and an environment. It is through this striving toward preservation-to perpetuate the lapse-that the human cultural world is produced. Since to philosophize about nature is to create nature, it is through work that the human labours to create its own nature as a manifestation of Nature. It is in this context that Schelling's conception of human activity is consistent with Marx's two types of work (externally forced labour and attractive work).

Schelling also differentiates between authentic and dead work. Work that operates on behalf of nature is authentic because it is aware of itself as being an archived manifestation of the process of nature as its condition of possibility. "However, as soon as I separate myself, and with me everything ideal, from nature, nothing remains to me but a dead object, and I cease to comprehend how a life outside me could be possible." Just as for Marx externally forced labour alienates the worker from both the process and the result of his or her labour, Schelling's notion of dead work involves separation; and, similar to Marx's theory of the commodity (and the related notion of reification), Schelling says that "nothing remains to me but a dead object," presumably detached from the transcendental process from which it arose. Work that detaches itself from the immanent activity of nature and instead attempts to control nature and worker alike is dead work. Since nature is characterized as being productively and in process for both Schelling and Marx in their own ways, we may make a critical distinction between work as a continuation of Nature's productive activity by man, and labour

\footnotetext{
${ }^{3}$ We may differentiate this from Aristotle's conception of generation and corruption where the life of particular beings goes through a pre-determined process of attempted actualization of their potential and inevitable decline.
} 
as a form of work, which is discontinuous and detached from nature's productive activity. Attractive work is attractive because it is synthetic and it melds with Nature's activity; external work is disjunctive in regards to nature's productive activity, and is thus alienated and alienating-alienated from nature's process and alienating for the worker. According to Marx, while alienated work is "repulsive" and "external" to the inherent creative process of nature, "attractive work" is not only a "spontaneous form" of labour, but is also "an activity regulating all the forces of nature" (Marx 1986, 60). Attractive work acts as a form of mediation between infinite nature and finite man, where man's labour is productive of culture (the production of a human world set up -as a lapse in relation to nature's activity - to preserve man as an entity) and finally, history, which acts as a bridge between the traditionally transcendent god and finite animality.

Hegel famously considers culture to be a "second nature," the latter being nothing but the product of man's work on nature and translated into history. Culture, as second nature, is thus a transformation of the infinite process of nature into an anthropomorphic product. Through this human work-activity, man imposes the preservation of a particular form on the infinite process of nature, and thereby imparts a lapse in part of nature's process, such that a small part of the process hardens into a structural form, or a state-of-power - which achieves a transformation of productive force into its institutionalization. Nature operates on the basis of force(s), while power is a cultural institutionalization of force reminiscent of man's active attempt to preserve itself. "Force is not to be confused with power. Power is the domestication of force. Force in its wild state arrives from outside to break constraints and open new vistas. Power builds walls" (Massumi 1992, 6).

It is in the form of the state-of-power (the translation of force into a static state of power) that capital is born, since the preservation of a particular static state uses nature's force against itself (Wirth 2000, xxiii) in a way that, instead of allowing it to open up new possibilities and ways of organizing work in the service of the "self-realization" of nature in the form of man (Marx 1986, 59), it actually contributes to its cancellation by detaching Nature's inherent excess and accumulating it in the form of (private) wealth. It is only in the form of culture that this form of accumulation is possible, since, on the level of Nature, there is nothing but ceaseless activity that exceeds the measure of any particular state. Through this counterprocess-which attempts to capture nature and render it static-that "the superabundant energies of the earth have been restricted by the exclusive investments of a particular world" (Wirth, xxiii). ${ }^{4}$ It is only through man, who translates nature into culture through the imposition of his own measure (as part of the creative process of history), that nature is capable of being falsely stored, and used against itself, in the service of the exploitation of one part of its activity against another. It is only through culture that nature is made into an object, and used as an infinite means to a finite end. By saying that Nature is infinite, this does not imply that there are an unlimited number of resources on earth to be exploited and used for the ends of capitalist accumulation. From the perspective of man, there is indeed an end in sight; but from the perspective of Schelling's Nature, which is absolutely indifferent to man, Nature is infinite and does not end with man.

While it can be argued that all species translate the infinite process of nature into a manifestation of their own measure (for example, through the perceptual apparatus used to mediate the contact of their organized bodies with their immediate surroundings), Schelling (and the German Idealists more generally including Marx) put the human in a privileged position in relation to other organisms because of this entity's unique capacity of the intellect to reflect nature back on itself, and thereby attain knowledge, or an image of nature. This is not to say that nature is not reflective of itself apart from man's intellect, but it is only through man that nature reflects itself in the form of a species that also imposes measure in the form of culture and history. It is through the capacity of reflection that man reflects one part of nature (subject) into/onto another part (object), and thereby uses one part against another part. Furthermore, it is through the work of culture, and the related building of institutions, that se-

\footnotetext{
${ }^{4} \mathrm{I}$ am using the term "state" here in all its ambiguity to refer both to the "state of being" (which implies a rendering static of flux) and the "political state" (which also implies a rendering static of flux).
} 
cond-nature becomes semi-autonomous and structured in a way capable of reproducing itself. It is thus that as an organization, the social organism of labour builds a repetition of itself based on the preserved power of Nature's institutionalized force in a way that attempts to match (or mirror) the process of Nature on an anthropocentric scale. Through knowledge (the image of Nature's reflection into subject-object form) nature becomes an object, and as an object, it is reflected back onto the labouring subject. By means of this reflection, the labouring subject becomes part of the objectified version of nature, and one part of nature is thereby used against another part. In other words, nature becomes an object when knowledge's reflection produces a form of objectified production that encapsulates workers as extensions of itself (i.e. objects). What this means is that through the institutionalization of force into a state-of-power, nature becomes unnatural production, and as a result, a particular form of production becomes objectified. In conformity with the other aspects of Nature's process the objectified result of the institutionalization of force is preserved in the form of capital claimed (and owned) by interested parties produced by the institutionalization of force, and coming to fill positions in the institutionalized framework made possible by culture's vocation as second nature in the service of history.

From Marx's perspective, the owners of production own the perpetuation of exploited labour, which is an object that perpetually produces more objects. The infinite process of Nature is transformed into an object-a particular form of cultural activity that becomes a social organism - and thereby comes to organize labour in such a way that preserves the excess of Nature's infinite movement in the form of power, wealth and capital.

\section{Knowledge}

What is particularly disturbing about this narrative is that knowledge is at the root of Nature's transformation into second nature, and from the latter, into a state-of-power and capital accumulation, since it is only through reflection that Nature is used against itself to produce institutional frameworks of repressive labour. This does not of course mean that all knowledge is complicit within the process of objectification and the institutionalization of force characteristic of capitalistic accumulation. Analogous to attractive work, there is a form of knowledge that is resistant to its appropriation by a state-of-power. Just as work aligned with Nature's process is conducive to self-fulfillment, knowledge that actualizes force and resists its accumulation by power is creative, as is evident in Schelling's creative philosophizing of Nature, and an intention of his Naturphilosophie project to address and explicate.

One implication of this is that the two types of labour are productive of two types of culture: communal culture and repressive culture. While communal culture is based on the premise that the fruits of work are shared, since all is a result of Nature's infinite process, repressive culture institutionalizes the fruits of labour in a way that subverts their distribution. It is thus only in attractive work that there could be relative freedom with respect to the parameters of this work, and the wares contributing to the production of a culture mimicking Nature's own flourishing, while externally forced labour leads to a culture of artificial scarcity and an extraordinary amount of resources spent on the base preservation of a particular state-of-power.

While Marx most clearly articulates a distinction between the two types of labourattractive work and repulsive labour-in the Grundrisse, particularly,in "The Fragment on Machines" it becomes clear what the implications for this distinction are for us today. In this section he argues that capital develops to a point where it begins to operate in such a way that it produces-and sustains-the conditions for its continued production in the form of fixed capital. The process of capitalist production, which, as noted earlier, is cumulative, archival and holistic, becomes united with the means of labour (i.e. workers) that actualize it. The means of labour are institutional frameworks for channeling force into accumulated power, and, according to the Marx of these pages of the Grundrisse, the means of labour pass through a series of developmental stages until they finally culminate in what he calls "an automatic system of machinery" (Marx 1993, 692). While he predominantly had factory equipment in mind, it is evident that the worker comes to inhabit the same infrastructural ground of 
labour that the machine actualizes to such a degree that it could be said that the worker's biological rhythms become entirely subsumed by the machinic apparatus-including the worker's intellect itself.

This process is reminiscent of the virtual infrastructure put in place by social media giants Facebook and Twitter. In both cases the machine (or virtual infrastructure) is not a tool utilized by the worker (which would act as a prosthesis requiring a certain level of skill to be utilized appropriately) but an abstract ground indifferent to the presence of the worker, besides their mere presence and "playful" activity. Since the worker is a "material quality of the means of labour" it is as though the machine takes the place of the condition of possibility for the existence of the worker, and is thereby "transformed into an existence adequate to fixed capital and to capital as such" (Marx 1993). While fixed capital-in the form of the machinic means of production and the virtual apparatus-becomes an indiscernible component of the labour process, or means of production, the worker becomes something of an extension of the machine or the virtual environment, since in both cases she merely provides the impetus, or the soul, for the actualization of movement.

Marx characterizes the machine as an automaton "consisting of numerous mechanical and intellectual organs, so that the workers themselves are cast merely as its conscious linkages" (Marx 1993). It is important to note that the workers are conscious linkages, and not merely physico-mechanical cogs in the machine: even in Marx's time the machine required a base level of conscious reflexivity for the perpetuation of the machine's activity to be sustained. This is why he considered capitalism to be vampiric, namely it requires the use of "living labour" to animate "dead labour" (Ross 2013, 29).

Analogous to this is the vast online infrastructure that requires countless hours of the "hive mind" (Lanier 2006) to work anonymously (and uncompensated) to sustain novelty to preserve the interest of its users, to maintain its basic functionality, and to further its cohabitation with the production and consumption of information (Terranova 2012, 33) It is thus at this stage of reflection that the production of nature as object, and the subsequent appropriation by the object of the subject in the cultural exploitation of one part of nature by another, that a secondary form of production arises as an alternative to nature's, one that, instead of enhancing life by producing new arrangements of being, produces dead objects made possible by the institutionalization of force as state-of-power. Detached from the ungrounded ground of Schelling's Nature, capitalistic second nature uses nature against itself by exploiting the reflective capacity of consciousness and knowledge to produce objects devoid of life. Power is appropriated to sustain a particular cultural-political arrangement of being at the expense of others, and the digital labour economy is a reflection of this at a later stage of development beyond the archetype of the machine Marx so presciently theorized under the heading of automaton. The natural activity of the worker, in the form of the average user of the Internet, is skimmed off-and monetized-and sold back to the worker/user in an objectified form. This objectified form, often called in-formation, is then utilized by the worker/user in a way that, in turn, informs the ways in which she is actualized, which is then fed back into this same system. As a result of this ceaseless reflexivity, the feedback loop becomes an ontological concept: It is knowledge's reflectivity in an objectified form, where activity is channeled in such a way that the worker/user recognizes themselves (or their "personal identity") in what is reflected back (fed back through the loop) at them, such that they becomes the ultimate ideological subjects, or absolute objects-"intellectual organs" (Terranova 2012). The worker/user's body becomes a platform for the transcription of force into power through the medium of information exchange (the body is rendered invisible, or ceases to exist outside of its registration into the amorphous abstraction of information). All that is left is an indifferent flow of information, its capture, and its feed-back into a system of capitalistic 'prosumption' where the worker doubles as a consumer who simultaneously consumes herself while she is consumed by the system.

In The Ages of the World Schelling speaks about degrees of power. Not only is there state-of-power, which I defined above as an institutionalization of productive force into state power, but, similar to Marx's notion of the "means of labour," for Schelling, nature's power also moves through certain stages. According to Schelling's doctrine of the three potencies, 
"every higher potency is an archetype of a lower" (Schelling 2000, 57). As he goes on to say, the existence of the higher requires the lower potency's unfolding of the "seed enclosed within it" (Schelling 2000). While not dialectical in the same way as Hegel's Geist, there is a certain movement theorized in this text from Schelling's middle period. For our purposes, we will extend Schelling's analysis to include digital labour as its culmination. The first potency is nature itself; the second is reflective consciousness; and the third is digital virtuality. While there is a vital force, or "world soul," moving through all three levels, it is only at the third level, that Schelling considers it to be at the level of what he calls the "God-head," which is a manifestation of the vital force itself. In an analogous way, it could be argued that it is on the level of virtual digitality that Nature manifests itself as such, in a fully reflective way. Since the movement goes from materiality to consciousness to immateriality, ${ }^{5}$ it is on the third immaterial level that both nature and consciousness are reflected back onto themselves in their "spiritual" form. "Hence, this heavenly, soul-like essence, which was concealed and asleep until now, first awakes with the appearance of the crisis in nature" (Schelling 2000). The crisis in nature is nature's being used against itself in the form of capitalist accumulation. On one side, this spiritual world-soul manifests itself as the "spiritual" aspect of Marx's commodity fetishism; on the other side, it is concretized as the network society of digital production, made manifest in and through its immaterial infrastructure or virtual world.

There are three phases in this re-interpretation of Schelling's theory of the potencies: Nature-materiality, culture-consciousness, and digital-immateriality. Characterized by ceaseless becoming, Nature's process produces entities-species, oceans, trees, and rocks. However, according to the second potency, human consciousness reflects nature in such a way that it is capable of being used against itself as part of a secondary process of manufacturing a second nature (culture and history). The intellect operates by taking things apart and analyzing them according to their component parts, thereby (as distinct from what Colletti considers understanding's vocation of locating the whole in the particular) reifying them into the form of objects; as culture becomes institutionalized into a state-of-power, man becomes an object amongst other objects. However, it is at the level of the third potency, when both Nature and Consciousness become overwhelmed by the excess of nature's force (which can never be entirely captured by the state-of-power) that the other two potencies (Naturemateriality and Culture-consciousness) become consolidated into the service of a third power that goes on to spiritualize both by reducing them to an image mediated and sustained by the flow of information. And it is in this third (digital) form-which happens to be when materiality is at its most immaterial-that Nature takes its revenge. The ceaseless process of force overwhelms man by bringing him into the guise of the third potency, which alienates consciousness from itself, and as the gods have done before, renders man impotent. Process continues to happen without man, and man falls into the abyss of a consciousness that is not his own-one that uses him against himself on a metaphysical level in a similar way that nature was used against itself at an earlier developmental stage.

\subsection{Immaterial Labour?}

At the level of immaterial labour nature is translated twice over, from nature into second nature, and from second nature into an image. Guy Debord had a glimpse of this when, in 1967-thinking predominantly about the impact of television-he wrote that "the image detaches itself from every aspect of life and fuses into a common stream in which the unity of this life can no longer be reestablished" (Debord 1967,6). Although in some passages he risks falling into a romantic idealization and yearning for a former "life" untarnished by technological mediation, the articulation of the image as a detached reflection of life lending an impression of itself as more real than reality itself, speaks to us today.

What, however, can be said to be produced immaterially? In contemporary social media the individual is removed from the product of their labour, since those who own the platform (Facebook, Twitter, Songza) also own the rights to the content and the trace of the activity of the user. However, from the Schelling perspective I am utilizing here, Nature does not stop

\footnotetext{
${ }^{5}$ For the purposes of this essay I will consider immateriality to be interchangeable with digital virtuality.
} 
being operative on the immaterial level. Since process occurs in all three potencies, digital virtuality is a productive activity that operates whether it is self-consciously noticed or not. So while it is free to sign up and use the service, the cost is the appropriation of the results of the productive activity in terms of its monetization, which is again detached from its potential as life-actualizing attractive work, and is further transformed into institutionalized power. However, it is obvious that immaterial labour is different from traditional forms of labour. No longer is anything actually tangibly produced. What is being produced is the vast infrastructure of an institutionalized version of the Internet, where every move is mapped and translated into information, which is in turn fed into a system of monetization and fed back into the "free" activity of individuals, only this time a little more rigid. What is produced is a vast database of information which takes the form of an archive of the individual's "personality" but which boils down to a series of "likes" and comments regarding quasi-political issues, tastes and patterns of consumption. Even the production and uploading of a digital photograph carries the traces of previous forms of "real life" interaction, but only as they are translated into a virtual image of what came before.

However, even (and especially) on the digital level there is ceaseless activity - people are constantly updating their profile, clicking on articles, ordering books, watching movies, or even just checking the weather. All of this constant activity translates into information, as both the trace and the condition of possibility for the activity itself, since information also contributes to the infrastructural form of online activity and the coding that produces the rules of the game. What then is information in this context? Against the traditional theory of information developed by Claude Shannon in his seminal 1948 article "A Mathematical Theory of Communication," (Shannon 1948) where he theorized information in terms of a message being transmitted in a relatively linear fashion in the sender-receiver paradigm of transmission, the concept of information relevant for our discussion of digital labour is qualitative and intensive.

Since information in-forms (produces forms of possible action or moves in the game) it contributes to the constitution of the subject operating in relation to the objectified conditions of its existence; it is pre-perceptual and operative on what Gilbert Simondon calls the level of the "pre-individual" (Combes 2013, 3). It is not yet actual because it makes actualities themselves possible. Information is a by-product of activity but it also constitutes activity by operating on the transcendental level. Schelling's theory of magnetism, conceived in terms of the spiritualization of matter as part of the vital impetus of Nature finds its counterpart in information. Information is a remnant of online activity, harnessed and used in the service of capital through its being captured from above by the state-of-power and used to in-form online activity. As information begins to in-form, by providing a form to an otherwise open system, it slowly begins to re-orient the future in terms of the in-formed structure of the past. Information derives from previous activity, it is a fundamentally retrospective by-product of process; when it is used by capital to in-form the future, it orientates the future in terms of the past thereby stifling any potential the past carries with it and the future could unfold. While the process of digital activity takes place endlessly, the result of the process (analogous to Nature's ceaseless activity in the first potency) is detached from its original impetus and used against itself, or against those subjects who become objects through the alienating power of the mechanisms of state capture. This third stage of development - digital virtuality - is considered immaterial because it is hyper-material; that is, since the walls it builds are purely formal, or what Marx called "ideological," they are impenetrable to force. While power is a derivative of force, the sedimentation of power puts in place an infrastructural arrangement that disallows force to actualize its de-territorializing potential. While force is wild-without constraint or formal arrangement-its institutionalization colonizes it by folding it back on itself. While power folds back, force folds forward. (This is similar to Kierkegaard's paradoxical notion of a repetition of the future.) Since it is operative on the level of Schelling's third potency, it finds nothing in its way, and as a result, it operates unaffected by anything other than itself.

History, which is always the history of culture, or second nature, is the result of the rendering static (or state-like) of the continual process-becoming of nature as a reaction to na- 
ture's continual process. For the state to fortify itself, particular contingent arrangements must be captured and preserved in their self-identity from the onslaught of nature's becoming in order to preserve them as they are, and to thereby lend the semblance of continuity and necessity to that which is discontinuous and contingent.

In more concrete terms we may say that the two types of workattractive and repulsiveare marked by the difference between, on the one hand, work that is in tandem with Nature's process, and which remains open to change and the becoming of life, and on the other hand, work that is not in tandem with Nature's process, and which seeks to use it against itself to thereby consolidate it through the mechanisms of objectifation and exploitation discussed above. Digital labour is not good or bad in itself, but, like the two types of work, it depends on the way it is utilized, since, according to our definition inspired by Schelling's theory of the potencies, the digital is a continuation of nature's productive activity by other means. Unfortunately the open-ended capacity of the Internet is becoming, like the physical resources of nature before it, privatized and monetized. This means that the result of the process of online activity is being captured from above by the same mechanisms operating to secure the state-of-power, and thereby used against those who consider themselves subjects or persons-the progenitors of the activity. To further complicate this picture, while the third stage is identified with the immateriality of the image, the image has now reoriented and recouped its material component. Through the use of mobile communication devices (or "smart" phones), the everyday life of embodied subjectivity has become mediated by information and constructed in terms of an image, not for itself, but for the other (capital). Location services on mobile devices map and track the coordinates of the device's user. By transfering data the owner is inadvertently "checking-in," and now that police forces have been given the authority to remotely de-activate camera funcioning on iOS devices in protest situations (Whittaker 2012), there is no longer any real difference between online and offline activities-all is activated, unified, and encapsulated in the web of virtual digitality.

While the spiritualization of matter in Schelling's magnetism was thought to animate and breathe life into the lower rung of existence, information plays this role on the level of digital virtuality, but in the opposite direction: instead of contributing to the production of novelty, information produces death. Just as for Hegel the stasis of being in identitarian thinking is akin to death, information, when utilized in the service of capital and turned against the prospect of change, alienates the process of production from the product and thereby safeguards the contemporary conditions of exploitable online activity by skimming off (or "valorizing") the excess of nature's product and preserving it in the form of wealth. While the constant law of nature for Schelling is change, the law of second nature, when colonized by capital, is the drive toward stasis by any means. Of course, as is well known, the cost of this drive toward stasis is war when nature's excess manifests itself in what Freud termed "the return of the repressed". The equivalent of the return in the digital realm is the slower but no less deadly-process of safeguarding all aspects of life under the guise of the password. To be digitized is to be amenable to the either/or logic of binary oppositionality (" 1 " or "0"), and all life, when transformed into the reflected image of digital virtuality, is castrated, cut off from its transformative potential, and rendered immobile. The era of the cyber-attack is upon us, where the equivalent of war takes place as the destruction-or pillaging-of information, and the "return of the repressed" takes on a digitally in-formed visage.

So what is being produced? In a digital labour economy it is information that is being produced. Information is a by-product of the process of work; work is the result of organized human activities operating on the basis of the attainment of a desired result. When all aspects of life become productive in this sense, we enter an economy not unlike that pointed out by the Italian autonomists in their notion of the social factory where every aspect of life is directly or indirectly linked to the production of capital. Through an emphasis on the collective aspect of labour-as seen in Marx's theory of machination in the "Fragment"-what they refer to as "knowledge" is produced as a by-product of the living interaction between people. As Terranova explains, for Autonomist Paulo Virno "Mass intellectuality - as an ensemble, as a social body - is the repository of the indivisible knowledges of living subjects and their linguistic cooperation [...] knowledge must come into being as the direct interaction of the 
labour force'" (Virno quoted in Terranova 2012, 45). Knowledge, which is made possible by the reflective capacity of consciousness, is the systematic use of information for a particular purpose. To say that there is a knowledge economy means that information is at the centre of the production process; that is, after a certain stage of development, and beyond the machination of the labour process of the "Fragment", of main importance is not the fact of production, but what may be termed the quiddity of production-the qualitative impetus or immaterial force by means of which production is capable of taking place. It is through the living interaction between people (not necessarily in an overtly labour-intensive environment) that production in the third potency of digital virtuality is made possible. By means of the "vampirical" operation of capital operating on this level, a dead object is produced. This dead object consists of the immaterial "stuff" of living interaction, and when captured from above and transformed into the state of information, it is detached from the living embodied engagement of interaction, and thereby monetized and used against the participants of interaction. The monetization of everyday life is complete when the most insubstantial, private, and even dignified aspects of human life, which can be compared to the arcane gestures analyzed by Adorno in Minima Moralia, are sold back to the living ground out of which they originated as something to be desired, sought after, and which are no longer available without a cost-labour-time and money (Adorno 2005). Without it even being noticed, force, which is part of the free ground of Schelling's nature-and a constitutive component of the human being -is translated into power, institutionalized, and transformed into the buttressing of a system of domination that, while advertised as free to use (e.g., Facebook), happens to gradually determine the ways in which interaction is conceivable. When all of social interaction becomes imaginable only in terms of what is available through this virtual infrastructure, human life becomes completely contained within the structure of capital, Marx's attractive work becomes attractive only in name and as advertised, and the dead object of living interaction is sold back to consume the consumer. Virtual infrastructure encapsulates all aspects of life by transforming them to the logic of its own capacity, i.e. the image, and when it accomplishes this, what Zuckerberg calls the "rewiring of social interaction" (Zuckerberg 2012) is complete because it becomes, not only an external attempt to capture an underlying living web of interaction, but the conditions of possibility for interaction itself. As he himself puts it: "By helping people form these connections, we hope to rewire the way people spread and consume information. We think the world's information infrastructure should resemble the social graph-a network built from the bottom up or peer-to-peer...We also believe that giving people control over what they share is a fundamental principle of this rewiring...our goal is to help this rewiring accelerate" (Zuckerberg 2012). It is up to the many unpaid labourers to forge the connections and highlight the networks - including the conformity of the very form that their interaction takes-that "accelerates" the process of rewiring that is necessary for the total integration of all aspects of living interaction (including affective, unconscious, gestural and imaginative components), and renders embodied engagement with a world a byproduct of what is made possible by the accomplished re-wiring. It gets to a point where the valorization of every aspect of life becomes indistinguishable from the contours of possible action, of relating with each other and imagining possibilities. What Kant called the transcendental conditions of possibility for experience, upon the totalized re-wiring Zuckerberg seeks, becomes identical with the results of the re-wiring; that is, the result of re-wiring would require an updated version of the Critique of Pure Reason as The Critique of Pure Wiring. The map and the territory become integrated as a digitized, monetized, and cognitively reduced program that conditions all aspects of human life, experience, and imaginaries.

Schelling's development of the notion of potencies, especially in Die Weltalter, is already beyond the basic framework of dialectical historico-materialist thinking while complementing it in a unique way. However, the Schellingian notion of potencies are undertheorized and therefore deserving of further scholarly and theoretical attention including their implications for a reconceptualization of digital labour. Schelling's potencies are a decidedly non-Hegelian concept in that they do not dialectically resolve themselves into a higher unity, but, instead, presuppose each other in a way that is not reducible to the previous terms. While they are part of a process of development, the larger framework of 
Schelling's "absolute idealism" sets them immanently within nature as the ungrounded ground for the free development of the spiritualization of matter and the materiality of spirit. Schelling works within a quasi-miraculous framework that sees the potencies abruptly emerge from the previous states in a way that indicates a rupture rather than a continuity. While the Hegelian dialectic may be considered a gradual process of development, mediated by a labourious "tarrying with the negative," Schelling's potencies seem to jump right out of their previous manifestations into a qualitatively different (and higher) form of organizational existence. This conception of development, when used to conceptualize digital labour, provides a propadeautic to Marxist understandings of digital labour that locate it in the realm of the "general intellect." While pre-digital labour required an embodied intellect oerating in unison with machines of production-including a pooling of abstract resources working in anonymous collaborative conditions of dispersed intellectual participatory-involvement-the phenomenon of digital labour requires a different ontological framework altogether since, when when idealist philosophy's Geist is made to stand for the digitial as it is here, it is seen as qualitatively different from other forms of labour, including those available to Marx's direct observation, when he theorized the general intellect as a condition of machinic embodiment.

I think that further attention may be paid to this area of Schelling's philosophy in order to tease out the further implications of its difference from Hegelian-Marxist variants of dialectical materialism for the understanding of digital labour. Important in this regard will be the untranslated Das älteste Systemprogramm des deutschen Idealismus. While its precise authorship is under dispute (it is written in Hegel's handwriting but reads more like Schelling's philosophy) it is reflective of the early formative years of Schelling, Hegel, and Hölderlin when they were theology students (and room mates) at the Tübinger Stift, as well as indicates the development of their engagement with Ficthe's thought as he attempted to grapple with Kant. Schelling considered Hegel's philosophy to be "negative" (as opposed to his own "positive" variant) because he thought it was enamoured with the systematization of a negativity of thought (negation being a central Hegelian concept). It also did not do justice to nature, treating it only as a secondary product used by spirit to recognize itself in the material form, but does not treat nature as generative in its own right. In this way Hegel's philosophy of nature is part of the well-rehearsed tradition of Aristotelianism that treated nature as the passive recipient of the active form or idea. By contrast, Schelling considered nature to be the predecessor for the development of mind and subjectivity, although the two may be said to be temporally identical and only logically sequential. Schelling's identity philosophy accounts for the unity between thought and nature by making thought a moment of nature (albeit its highest manifestation), while Hegel treats nature as the negative moment of thought's development.

By treating the digital as Schelling treated spirit (as I am doing here)-as a quasi-divine essence, or force, which does not transcendend the materiality of nature, but which is constitutively immanent to the development of nature itself-the relationship between digital and non-digital forms of labour and the ways in which the former offer both a break from, and a continuity of the latter. One contradiction, then, between Schelling and Marxist conceptions of development is seen through the notion of potencies. Whereas Marx was heavily influenced by the Hegelian dialectic which plods along negatively through a succession of negations, Schelling's potencies work more like ruptures that bring out more complex manifestations while still remaining immanet to the earlier manifestations. These earlier manifestatiosn are preserved, and they exist alongside the higher potencies. This is similar to the Hegelian Aufhebung (which simultaneously cancels and preserves) minus the negating component of sublation. One thing Marxists can learn from Schelling's philosophy is the way that nature incorporates different levels of complexity as different potencies of the same substance. Early disagreement, and eventual break with Hegel indicates a more fundamental disagreement about the status of nature. While for Hegel work is an external operation leading to a dialectical development through negation and Aufhebung (as demonstrated in through the famous master-slave analysis in the Phenomenology of Spirit), Schelling's work is immanent to the process of nature itself, since it does not transcend nature, and intellectual or spiritual/digital work is material work by other means since it too 
participates in and as nature but only as a higher potency. While "higher" seems to imply better, this is not the case; both participate in the Lebenskraft of nature's vitality, albeit in a more organized fashion.

\begin{tabular}{|c|c|c|}
\hline Concept & Marx & Schelling \\
\hline Dead Labour & $\begin{array}{l}\text { Repulsive external- } \\
\text { ly forced, exploita- } \\
\text { tive labour; ex- } \\
\text { change-value ori- } \\
\text { ented. }\end{array}$ & $\begin{array}{c}\text { Nature used } \\
\text { against itself and } \\
\text { treated merely as } \\
\text { product (capital } \\
\text { accumulation) and } \\
\text { not process. }\end{array}$ \\
\hline Living Labour & $\begin{array}{l}\text { Attractive work; } \\
\text { leads to self- } \\
\text { actualization. Use } \\
\text { value oriented. }\end{array}$ & $\begin{array}{l}\text { Work done in rela- } \\
\text { tion to nature's } \\
\text { inherent productivi- } \\
\text { ty, which "creates" } \\
\text { alongside nature } \\
\text { and contributes to } \\
\text { the creation of na- } \\
\text { ture itself. }\end{array}$ \\
\hline State-of-power & $\begin{array}{l}\text { Capital accumula- } \\
\text { tion. E.g., the own- } \\
\text { ership of the infra- } \\
\text { structure of the } \\
\text { means of produc- } \\
\text { tion. The State. }\end{array}$ & $\begin{array}{l}\text { Domination of na- } \\
\text { ture by using its } \\
\text { productivity to op- } \\
\text { press by securing } \\
\text { resources and in- } \\
\text { frastructure to } \\
\text { deaden alternative } \\
\text { potentials. }\end{array}$ \\
\hline Force/power & $\begin{array}{l}\text { Revolutionary po- } \\
\text { tential; general } \\
\text { intellect/ldeology, } \\
\text { capitalistic systems } \\
\text { of domination. }\end{array}$ & $\begin{array}{l}\text { Chaotic energies of } \\
\text { the ungrounded } \\
\text { ground as nature's } \\
\text { process/ Institu- } \\
\text { tionalized force } \\
\text { (stymying process } \\
\text { into product). }\end{array}$ \\
\hline Capital & $\begin{array}{c}\text { Surplus labour in } \\
\text { the service of ex- } \\
\text { change-value. }\end{array}$ & $\begin{array}{c}\text { Nature as accumu- } \\
\text { lated product and } \\
\text { limited/controlled } \\
\text { process. }\end{array}$ \\
\hline
\end{tabular}

Table: Conceptual Comparison of the Framework of Marx's and Schelling's theory of labour 


\section{2. "What is to be done?"}

Lenin's famous question stands for an entire attitudinal disposition, and worldview of praxis. Within Marxist ontology there is a dialectical relationship between the individual and its conditions for existence (Marx 1986, 54). The conditions of existence simultaneously function on the immediate level of actually existing labour relations, class conflict, economic factors, etc., and on the mediating level of the transcendental conditions of possibility for the existence of the individual and the related possibilities of being. Theorists such as Althusser and Foucault look at the processes of subjectivation that result from the interplay between force and power in their social manifestation. Of particular interest in this regard is Foucault's later work, which emphasized the role of the constitution of selfhood in the displacement and rearticulation of power in ways that attempt to avoid the immediate consumption of living interaction by disciplinary regimes and capital. Through various programs of the "care of the self" - which Foucault performs a genealogical analysis of in History of Sexuality Vol. 3-he illustrates the ways in which power is displaced, externalized and rendered impenetrable to the internal constitution of individual subjectivity when structured in terms of alternative disciplinary regimes of iterated embodiment. In other words, according to the late Foucault it is possible to disengage from institutionalized frameworks of power by building a micro-institution of self-hood that does not completely rely on the immanent arrangement of the alreadyestablished regime of power relations (states-of-power), but takes its nourishment from the sublimity of nature's force, which cannot be readily incorporated into the transcendental framework of the already-existing system. Through the facilitation of selfhood, power is transformed back into force, and force is by definition inarticulable and therefore incapable of falling into the statics of state-of-power. By forging a Foucaultian "self," the immateriality of digital virtuality rubs up against the materiality of existence in a way that renders it incapable of incorporating this alternative form of constitutional arrangement into the categories of the same, despite the accelerated terms of the "re-wiring" already accomplished by the likes of Zuckerberg.

In one sense a self is a distinct nodal point in the already-established network, but, by virtue of its alterity (its inability to be completely incorporated), its modality is not totalizable, and therefore, it is incapable of being recognized and incorporated into the network in place. In Kantian terms, the Foucaultian self is of the sublime component of nature that cannot be subsumed by the available categories. The sublime is Nature's revenge as it pierces through the hubris of second nature's use of nature against itself, and the impetus for the revolutionary fervor that arises, not as a product of the re-wired environment, but despite it. While culture-consciousness and digital-immateriality are other than nature-materiality, like Schelling's three potencies on which they are modeled, they are immanent to each other. So while nature can be thought of as culture's constitutive outside, it is outside only insofar as the inside is dependent on it for its existence. We may say that, following S.J. McGrath's The Dark Ground of Spirit: Schelling and the Unconscious (2012), that nature is culture's unconscious, and that the return of the repressed is the return of Schelling's Nature itself, which is both productive and destructive. The return of Nature (making itself felt in the most minor power outage) renders digital-immateriality obsolete, incapable of sustaining itself, and making clear that Nature is deeper than information can conceive, and that, in fact, it is abyssal, or what Schelling calls "the abyss of freedom".

While an individual is only what it is in relation to its history and material conditions, selfhood is akin to what Deleuze and Guattari called an assemblage, and in this case, it is an assemblage of the history and material conditions for the individual, only re-organized around the centre of its propensity for activity. More concretely, the conditions Marx has in mind in terms of the historical and material conditions for the individual are those of exchange value and the commodity form, which are themselves abstractions of the relations of production. In an exchange economy, like the products and medium through which exchange occurs (i.e. money), individuals come to be reduced to objects for themselves and others. Against this process of objectification, the Foucaultian self's modality of construction taps into the resources of Nature's pure force and (re-)organizes itself around the virtual potential contained 
in and as a constitutive part of these forces. In the capitalist organization of production, the individual is valued according to the calculus determining the value of her labour. The price put on the individual's labour is reflective of the commodification of the individual-the determination of its value by market forces-and its alienation, since it is now split between itself and its recognized exchange value. Exchange value does not develop according to the individual's natural abilities, which they would if these had recognizable intrinsic value, but rather, according to the wage determined by the competition between the owners of production. The move to externalize the labourer from the products of her labour-and from herself-is part of the repulsive labour Marx diagnoses as inhibiting the self-fulfillment of the one who performs the labour. Digital labour often carries with it the imagined belief that it is immaterial, and thus disconnected from the embodied activity of work. This alienation directly results from the move toward objectification, and the reduction of the labourer to its status as individual reflected as a "re-wired" image of virtual-immateriality. Alternatively, the Foucaultian self clogs up these networks of power by constructing an aggregate of these relations in a way that defies the logic of the system by tapping into the pure force of nature, thereby becoming other to the system, even as it remains a constitutive node in it. Just as Schelling says that to philosophize about nature is to create it, similarly, to philosophize about the digital is to forge the contours of a self which works on behalf of nature, and introduces the constitutive outside (or culture's unconscious) into the very conditions of the digital image, thus exposing it to its inherent potential for auto-poietic destruction of itself by itself.

\section{References}

Adorno, Theodor. 2005. Minima Moralia: Reflections on a Damaged Life. Translated by E.F.N. Jepcott. London: Verso.

Colletti, Lucio. 1979. Marxism and Hegel. Translated by Lawrence Garner. London: New Left Books.

Combes, Muriel. 2013. Gilbert Simondon and the Philosophy of the Transindividual. Translated by Thomas LaMarre. Cambridge: MIT Press.

Debord, Guy. Society of the Spectacle. Translated by Black \& Red on Marxists.org. Accessed on November 21, 2013. http://www.marxists.org/reference/archive/debord/society.htm

Deleuze, Gilles and Félix Guattari. 1987. A Thousand Plateaus. Translated by Brian Massumi. Minneapolis and London: University of Minnesota Press.

Foucault, Michel. 1986. The History of Sexuality Volume 3: The Care of the Self. Translated by Robert Hurley. New York: Random House.

Fuchs, Christian and Sebastian Sevignani. 2013. What is Digital Labour? What is Digital Work? What's their Difference? And why do these Questions Matter for Understanding Social Media? tripleC-Cognition, Communication, Co-operation: Open Access Journal for a Global Sustainable Information Society 11 (2): 237-293.

Heidegger, Martin. 1985. Schelling's Treatise on the Essence of Human Freedom. Translated by Joan Stambaugh. Athens, Ohio: Ohio University Press.

Lanier, Jaron. 2006. Digital Maoism: The Hazards of the New Online Collectivism. Edge. Accessed January 9, 2014. http://www.edge.org/conversation/digital-maoism-the-hazards-of-the-new-onlinecollectivism.

Marx, Karl. 1986. From the Grundrisse In Karl Marx: A Reader, edited by Jon Elster. Cambridge: Cambridge University Press, 29-62.

Marx, Karl. 1993. Grundrisse. Translated by Martin Nicolaus. London: Penguin Classics. Reprint Edition.

Massumi, Brian. 1992. A User's Guide to Capitalism and Schizophrenia. Cambridge: MIT Press.

McGrath, S.J. 2012. The Dark Ground of Spirit: Schelling and the Unconscious. New York: Routledge.

Ross, Andrew. 2013. In Search of a Lost Paycheck. In Digital Labour: The Internet as Playground and Factory, edited by Trebor Scholz, 13-32. New York: Routledge.

Schelling, F.W.J. 2000. The Ages of the World. Translated by Jason Wirth. New York: State University of New York Press.

Schelling, F.W.J. 2004. First Outline of a System of Philosophy of Nature. Translated by Keith Peterson. New York: State University of New York Press.

Schelling, F.W.J. 1976. Werke: Historische-kritische Ausgabe. Translated by Keith R. Peterson. Edited by Hans Michael Baumgartner, Wilhelm G. Jacobs, and Hermann Krings. Stuttgart: FromannHolzboog. 
Shannon, Claude. 1948. A Mathematical Theory of Communication. The Bell System Technical Journal 27: 379-423, 623-656.

Terranova, Tiziana. 2012. Free Labour. In Digital Labour: The Internet as Playground and Factory, edited by Trebor Scholz, 33-57. New York: Routledge.

Whittaker, Zack. 2012. Apple Patent Could Remotely Disable Protesters' Phone Cameras. Accessed November 13, 2013. http://www.zdnet.com/apple-patent-could-remotely-disable-protesters-phonecameras-7000003640/.

Wirth, Jason. 2000. Introduction. In Ages of the World, translated by Jason Wirth. New York: State University of New York Press.

Zimmermann, Rainer E. 2005. Otherland Revisited: Philosophical Implications of Artificial Worlds. In Towards Otherland: Languages of Science and Languages Beyond, edited by

Rainer E. Zimmermann and Vladimir G. Budanov, 29-44. Kassel: Kassel University Press.

Zuckerberg, Mark quoted in DeBord, Matthew. 2012. Facbook Files for IPO, Zuckerberg Outlines his Vision for 'Rewiring' Us. The Breakdown. Accessed November 14, 2013.

http://www.scpr.org/blogs/economy/2012/02/01/4494/facebook-files-ipo-zuckerberg-outlines-hisvision- $/$.

\section{About the Author}

Kevin Mitchell

Received his PhD from Trent University in Cultural Studies in May 2014. His dissertation was on the influence of the Kantian transcendental turn for contemporary theory and culture with reference to the so-called concussion crisis in American football, South Park's problematization of the discourse surrounding this crisis, and the literary output of novelist and poet Charles Bukowski. Kevin believes that a Cultural Studies without philosophy is blind, and a philosophy without a socio-cultural component is empty. 